REVISTA CIENCIAS BIOMÉDICAS

\title{
EN PORTADA
}

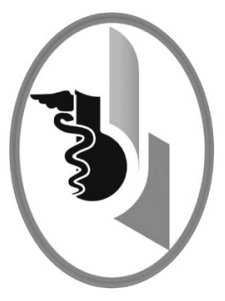

2016;7(2):201-202

\section{EDUARDO FERNÁNDEZ GUERRERO}

Nació en la población de Arjona, departamento de Bolívar, el 21 de abril de 1932, cursó estudios de bachiller superior en la Universidad de Cartagena entre los años 1944 - 1949. Al año siguiente, con 17 años de edad, se fue a la ciudad de Bogotá y allí realizó estudios en la Universidad Nacional de Colombia, en donde obtuvo el título de Bacteriólogo y Laboratorista Clínico en 1954 con la tesis Viscosidad sanguínea en el estado puerperal y en los individuos normales, - mientras estudiaba fue preparador de bioquímica por dos años en la misma universidad.

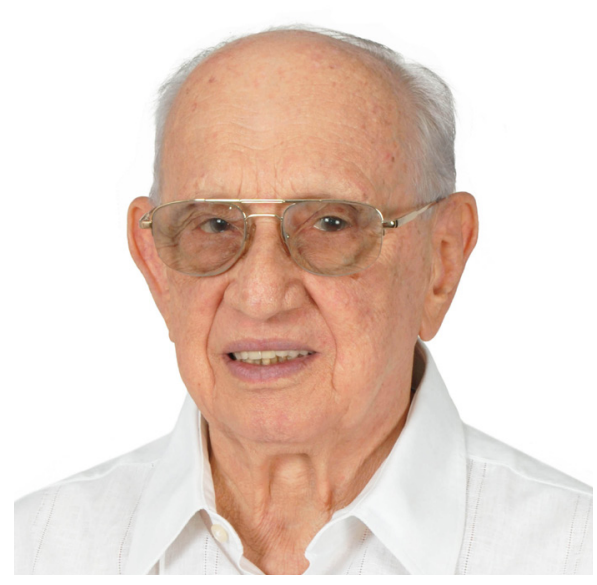

Inmediatamente regresó a la ciudad de Cartagena y en 1955 inició el desempeño de su profesión, la cual continúa ejerciendo a diario, esto es, 62 años de servicio a la ciudad y a la región. Desde su laboratorio clínico ha sido soporte para el ejercicio de la profesión médica en épocas muy diferentes, ofertando siempre técnicas acordes al momento y a la vanguardia en la región; siempre atento al desarrollo y aparición de nuevas tecnologías en el campo de la bacteriología, la bioquímica y el laboratorio clínico.

Por más de cinco años, antes de la llegada de las pruebas inmunológicas al final de la década de los sesenta del siglo XX, ofreció a la región Caribe colombiana la prueba de Galli Mainini para el diagnóstico precoz del embarazo. Tenía en su laboratorio una cantidad suficiente de sapos machos para realizar la prueba, que consistía en inyectar orina de la mujer supuestamente embarazada en el saco ventral del animal y buscar horas más tarde en su cloaca la presencia de espermatozoides. Si estaban presentes la prueba era positiva. Al parecer fue el único que en Cartagena brindó ese recurso de diagnóstico. El semillero de investigación HISTORI-MED en su videoteca tiene un video donde el doctor Eduardo Fernández Guerrero explica la prueba de Galli Maini. https://www.youtube.com/channel/UCHPKcFWFTTUEMxCwVYEwbLA

Desde su llegada a Cartagena, y por cinco años, fue el jefe del Laboratorio Clínico y del Banco de Sangre de la Casa del Niño, hoy denominado Hospital Infantil Napoleón Franco Pareja, institución de atención en salud que ha cumplido, y lo continúa haciendo, una de las labores más loables de la región en beneficio de la niñez. Para los inicios de la segunda mitad del siglo XX ese laboratorio clínico era el más avanzado que tenía la ciudad de Cartagena. Desde siempre esta institución privada sin ánimo de lucro, de una u otra manera, ha 
estado anexa o en convenio con la Facultad de Medicina de la Universidad de Cartagena.

A parte de eso, por treinta y tres años el doctor Eduardo Fernández Guerrero fue profesor de la Universidad de Cartagena, dedicado a la docencia teórica y práctica con exclusividad de la bioquímica, definitivamente el área de su preferencia. Estuvo en todos los peldaños de la carrera docente: instructor (1960-1962), profesor asistente (1963-1966), profesor asociado (1967-1970) y profesor titular (19711982). Pasó a la condición de jubilado de acuerdo a la normatividad vigente, no obstante, al año siguiente regresó como docente de cátedra de la asignatura de Bioquímica por otros doce años.

Prefirió ser profesor que directivo, por lo cual siempre esquivó los encargos administrativos, aunque cumplió labores como miembro de diferentes comités de la Facultad de Medicina. Fue fundador del Colegio de Profesionales de Laboratorio Clínico de Bolívar en 1979 y vicepresidente nacional de la Federación Colombiana de Laboratorio Clínico entre 19821984. Miembro de las sociedades internacionales: American Association for Clinical Chemistry y de The New York Academy Science.

Realizó cursos de posgrado como alumno especial del Doctorado de Bioquímica en la Universidad Autónoma de México en 1964, participó en proyectos de investigación y alcanzó reconocimiento equivalente a Maestría en Bioquímica. Incrementó su preparación asistiendo al Centro de Investigaciones Biológicas de Madrid en 1971. A Río de Janeiro acudió en 1984 para realizar estudios sobre los avances en el uso de la electroforesis para el diagnóstico en laboratorios clínicos.

En el año 1997, la Universidad de Cartagena cumplió 170 años de existencia y dentro de las actividades a desarrolladas, el honorable Consejo Académico lo seleccionó como uno de los docentes a recibir la Medalla del Sesquicentenario de la Universidad de Cartagena, por sus méritos académicos, profesionales y personales.

Entre su producción académica destaca un artículo que escribió en lengua inglesa y que tituló: Kinetic characteristic of cysteine desulphydrase in the liver and other biologic species. Fisiology and comp. Biochem. 1973;458:81-85.

Los siguientes artículos fueron publicados en una importante revista española: [1] Determinación del DNA en orina de individuos normales y nefropatías. Revista Laboratorio.1968;47(284):101-104.

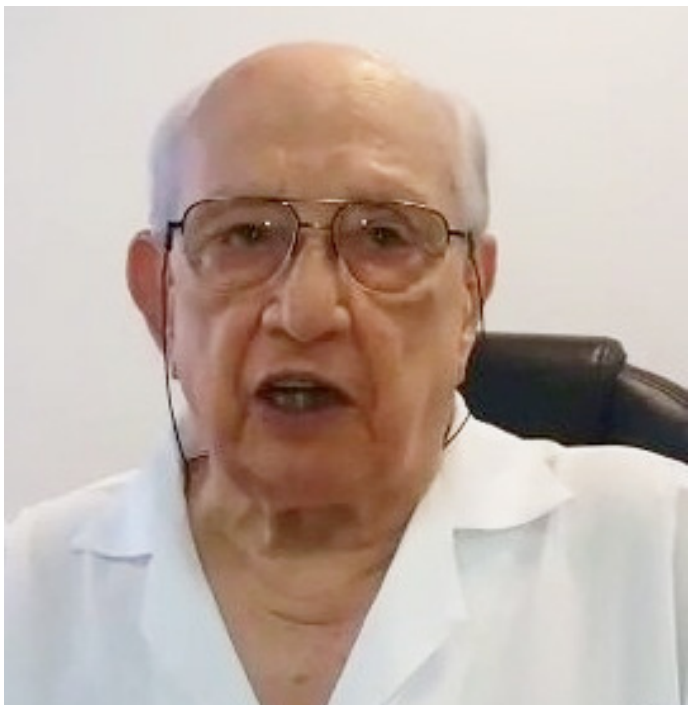

[2] La colinesterasa eritrocítica humana y su relación con la resistencia globular. Revista Laboratorio.1970;56(297):209-215. [3] Triglicéridos y lipoproteínas en la clasificación de las dislipidemias familiares. Revista Laboratorio. 1973;59(333):201-2016. [4] Un perfil bioquímico para el estudio de las alteraciones en el metabolismo de los hidratos de carbono. Revista Laboratorio. $1981 ; 72(427): 1-7$.

Además publicó en revistas de la Universidad de Cartagena: [1] Consumo de oxígeno en eritrocitos humanos y diferentes especies biológicas. Revista Ciencia Tecnología y Educación. 1981;1:4-5. [2] Influencia de la hemoglobina fecal y otras hemoglobinas en la determinación de la hemoglobina glicosilada. Ciencia Tecnología y Educación. 1983;3(4):55-59. [3] Las lipoproteínas y el diagnóstico clínico por el laboratorio. Revista de Química y Farmacia. 1985;3:18-21.

Así las cosas, el doctor Eduardo Fernández Guerrero tiene 85 años de edad actualmente y sigue activo al frente de su laboratorio clínico, ofreciendo soporte actualizado de laboratorio clínico a los profesionales de la medicina de la ciudad y la región para beneficio de sus pacientes. Por sus manos han pasado numerosas técnicas de laboratorio y ha vivido todo el desarrollo de la bioquímica desde la segunda mitad del siglo XX. 